\title{
sciendo
}

\section{What it is to be an Intentional Object}

\author{
Nicola Spinelli \\ University of Warwick \\ DOI: $10.2478 /$ disp-2016-0004 \\ BIBLID [0873-626X (2016) 42; pp. 93-112]
}

\begin{abstract}
This paper is about a certain view of intentionality, a problem faced by the view, and two ways in which, it has been proposed, the problem might be solved. The view is that every intentional state has an intentional object. The problem is that the putative intentional objects of some intentional states do not, or even cannot, exist. The two strategies to solve the problem and secure the view are those implemented by Tim Crane in his article "Intentional Objects" (2001). In this paper I argue that both Crane's implementations and the strategies in general are unsuccessful. By way of (partial) overview, I also discuss other ways in which the problem has been addressed.
\end{abstract}

\section{Keywords}

Intentional objects, intentionality, Tim Crane, entity, existence.

\section{A view and a problem}

For a mental state to be intentional is for it to be about, or directed at, something. Thought, love, belief, desire, fear, doubt are types of intentional states: because to think is essentially to think of something, to love is to love something or someone, to believe is to believe that such-and-such is the case, and so on. Providing one shares this intuition, how should one cash it out conceptually? Here is a straightforward way to do so. For every intentional state, there is something which the state is about: its intentional object. The characteristic aboutness of intentional states is simply the capacity, on the part of those states, to acquaint subjects (minds) with intentional objects. Call this construal of intentionality the Straightforward View.

The view is certainly straightforward, but it need not be correct: as philosophers started to realise at least as far back as in the $4^{\text {th }}$ and $3^{\text {rd }}$ century $\mathrm{BC}$, there seem to be counterexamples to it. These

Disputatio, Vol. VIII, No. 42, May 2016

Received: 12/11/2015 Revised: 20/02/2016 Accepted: 19/04/2016 
are mental states that are intuitively intentional (i.e., in some sense, about something), but that, one may argue, falsify the claim that all intentional states have an intentional object - that for every intentional state there is something which the state is about.

Take, for example, such states as my thinking of Santa Claus or the Quinean round square cupola on Berkeley College. Intuitively, there is a sense in which these states are about something. Thus, they should count as intentional. According to the Straightforward View, if they are intentional it is because there is something which they are about - because they have an intentional object. Santa Claus and the round square cupola on Berkeley College, however, respectively do not and cannot exist. If that is so, one might ask, in what sense are my thinking of Santa or the cupola about something? Should we not say that, in fact, there is nothing which those states are about - that they have no intentional object? If we should, then the Straightforward View — the most immediate way to make sense of our intuitions about intentionality — must be discarded.

\section{Some options}

There are many possible reactions to the problem. Of the philosophers who have concerned themselves with these matters, some have attempted to save the Straightforward View, while others have taken different courses. Which course is best to take - that is a hard nut to crack. Some options, however, clearly will not do. Here is one. Suppose you want to salvage the Straightforward View; a natural way to do so would be simply to deny that mental states that (mis)behave the way my thinking of Santa or the cupola do are intentional. This, however, would hardly be satisfactory. For one thing, it seems that thoughts about existents and thoughts about non-existents instantiate the same type of mental state, namely, thought. As such, they should admit of a unitary account. However, if one takes thoughts about existents to be intentional and thoughts about non-existents not to be intentional, it is not clear that one is then in a position to provide such a unitary account. The same is true of any type of intentional state. Secondly, there surely is some intuitive sense in which, if I am thinking of Santa Claus, I am indeed thinking about something. It seems that an account of intentionality that flatly denied this 
would just be inadequate.

Here are two alternative and more promising approaches (as we shall see, examples of both can be found in the literature). The first is to admit that some intentional states have no intentional object. This would mean abandoning the Straightforward View and its characteristic construal of intentionality and aboutness, perhaps in favour of a construal in terms of propositional representation and conditions of satisfaction. According to this account, which we may call the Propositional View, for a mental state to be intentional is just for it to propositionally represent the world as being a certain way. If, as is the case with Santa Claus and the round square cupola on Berkeley College, the propositional content of a mental state includes some non-referring terms, then that content is just false, and the state represents the world wrongly. However, insofar as it does represent the world, it counts as intentional. This preserves the aboutness, and thus the intentionality, of the relevant states, while avoiding the problem of their alleged intentional objects being non-existents. This is John Searle's view in Intentionality (Searle 1983: Ch. 1, esp. 11-13, 16-18).

One worry with the Propositional View is that it seems go hand in hand with descriptivism about proper names, i.e., with the view that for every proper name $a$ there is a collection $D$ of descriptions that constitutes the meaning of $a$. Following powerful criticisms (most famously Kripke 1980), descriptivism has fallen into disrepute. This may be taken to speak against the Propositional View of intentionality. But critics of descriptivism need not be correct: the view still has some stout endorsers (unsurprisingly, Searle is one of them). Another (and perhaps more pressing) problem is that while it is plausible that all intentional states rely on, or are made possible by, a propositional representation of the world - i.e., on an intentional state that is propositional in nature - it is not obvious that all intentional states are propositional in nature. Phobias (peculiar kinds of fear) are a case in point. For example, plausibly you can only have arachnophobia if you are able to entertain the thought that there are spiders in the actual or even in some possible world; to such an extent, arachnophobic intentional states rely on propositional states. Yet, it is not obvious that the arachnophobics' obsessive and irrational fear of spiders can be reduced to fear, say, that there may be spiders in the room (or even in the actual or in some possible world), 
that spiders may harm them, and so forth. It is therefore not obvious that arachnophobic intentional states are themselves propositional in nature. If this line of thought is correct, then there may be counterexamples to the core claim of the Propositional View, i.e., to the claim that a state's intentionality just is its propositionally representing the world.

Some philosophers, however, do not wish to forsake the Straightforward View, and are thus unwilling to buy into the Propositional View. These philosophers might hold their ground by claiming that items such as Santa Claus and the round square cupola on Berkeley College have, in fact, an existence of sorts, and that, in this sense, they are not problematic for the Straightforward View. Let us call this option Existence Defended View. This is, in fact, a family of accounts differing from one another on the basis of how they implement the central idea that seemingly non-existent intentional objects nonetheless exist.

One way to implement the idea is to endorse Franz Brentano's early view (the one offered in Psychology from the Empirical Standpoint, 1874), according to which intentional objects, as such, exist mentally. ${ }^{1}$ Thus, even though Santa Claus himself does not exist, insofar as I think of him he exists in my mind, and is therefore not problematic for the Straightforward View. The mental existence of intentional objects is called by Brentano 'intentional inexistence.' This terminology is traced back to the Scholastics by most commentators and to Aristotle by Brentano himself (Brentano 2015: 93). Be that as it may, talk of objects existing merely in the intending mind can undoubtedly be found at least as far back as in the early Stoics, Zeno and Cleanthes (Caston 2001, 2007).

One difficulty with this approach is that, as one may argue, it is phenomenologically inaccurate. This can best be seen in cases of existent intentional objects. Suppose, for example, that I am thinking about my house. Then my house should be the intentional object of my current mental state. On Brentano's view, however, this cannot be: since intentional objects as such are mental items, the intentional object of my current mental state will be, at best, a mental proxy for my house. And yet it seems that when I think of my house, I

\footnotetext{
${ }^{1}$ Brentano came to repudiate this view later in his career.
} 
think of it, not of a mental proxy. This, notice, is not to say that no intentional object is a mental item. For example, I might be thinking about my belief that Santa Claus does not exist - and since beliefs are mental items, that particular belief, i.e., the intentional object of my thought, will be a mental item, too. However, it will not be a mental item in virtue of its being an intentional object (as Brentano instead would have it).

Alternatively, one might turn to the distinction, due to B. Russell, between being and existence (Russell 1996: 449-450). The thought is that, in order to be an entity, something need not exist: it might just have being. Thus, there will be a sense in which Santa and the cupola, although they do not exist, are entities. And if there is a sense in which they are entities, then there is a sense in which they are not problematic for the Straightforward View. Indeed, the reason why, for Russell, we should make the distinction in the first place is that it is the only, or at least the best way of explaining the fact that we can think about non-existents. One problem here is that the distinction between being and existence is rather obscure. Moreover, if the distinction is admitted solely on the basis that it (supposedly) makes non-existent intentional objects intelligible, arguably it will be obscure and ad hoc.

Yet another way to implement the Existence Defended View is to endorse some form of Meinongianism. Meinong's own strategy in Über Gegenstandstheorie (1904) was to distinguish between the Sein of an object (its existence or subsistence) and its Sosein (its being determined in a certain way), and to claim that the two are independent. The idea is then that Santa Claus, insofar as he is determined in a certain way (i.e., insofar as he has Sosein), can be the intentional object of, e.g., my thinking of him — even though, on the other hand, he has no Sein. Of course, one should then explain how it is that something can be determined in any way, and be thought about, and yet not exist - which seems exactly the problem faced by the Straightforward View. I should mention that Meinongianism can take several forms, the most interesting of which is perhaps Modal Meinongianism (see for example Priest 2005 and Berto 2013). Discussing new forms of Meinongianism, however, would take me too far afield; so I will leave those views to one side. 


\section{One more option and two routes to secure it}

There is, however, at least one more option for endorsers of the Straightforward View. Let us assume, contra Russell's 1903 position, that to be an entity is just to exist in the actual world. Let us also suppose, contra Brentano, that when — say — we think about something, the object of our thought does not, from the sheer fact that it is what we are thinking about, exist in our minds; and that, as a consequence, intentional objects are not, as such, mental items (though some may well be). In so doing, we assume that what we think about when we think of Santa Claus 1) exists neither extra-mentally (which is uncontroversial) nor mentally in the actual world, and 2) since it does not exist in the actual world, it is not an entity in any sense. In other words, we assume that what we think about when we think of Santa Claus is, quite literally, nothing.

Notice now, and this is the core insight of the proposal, that the fact that the objects of some intentional states do not exist — i.e., the fact that they are not entities — is only a problem for the Straightforward View if it is required, for something to be an intentional object, that it be an entity in the first place. That is, the Straightforward View really has a problem with intentional objects that do not exist only if the following claim:

(A) To be an intentional object is to be an entity

is true. What endorsers of the view should do, then, is to find a way to reject $A$.

There are several strategies to achieve as much. For example, one may identify A with what is often called the relational view of intentionality, according to which intentional states are "about" something because they relate a subject (a mind) to an entity — the background thought being that for a relation to obtain its relata must first exist — and then attack such a view directly, perhaps on the ground that the existence of the relata is not a necessary condition for a relation to obtain. But one might also take different, indirect routes: strategies that explore the implications of claim A and argue that, since these implications are incorrect, claim A must be false. I am interested in two of these. (In fact, I am not sure there are others in the literature.) One, which I shall call Route 1, attacks A by appealing to the kinds to 
which, if A were true, intentional objects should belong. The idea is that if intentional objects were entities, they should belong to certain kinds; but — so the strategy goes — they do not belong to any of those kinds; therefore, A is false and intentional objects, as such, are not entities to begin with. The second strategy I am interested in, Route 2, attempts to reject A by showing that the terms 'object' and 'entity' do not admit of (unrestricted) intersubstitution. But, so the strategy goes, they would if A were true. Thus, A is false, and intentional objects, as such, are not entities in the first place.

Both strategies are implemented by Tim Crane in his 2001 article "Intentional Objects" (henceforth, IO). In more recent works, e.g. Crane 2012 and Crane 2013, Crane has put things differently and, I think, more effectively. This is not surprising: as I shall argue, Route 1 and 2 are in general unsuccessful and had better be abandoned. In order to show that that is the case, I will first attack Crane's implementations, and then generalise my objections to the strategies as such. Admittedly, the generalisation is fairly straightforward; however, it is an important step, because it makes the discussion relevant not only to Crane's work, but to the whole debate on intentional objects.

But before I go on to discuss Route 1 and Route 2, I need to say something more about claim A. It admits of two readings. On one reading, to be an intentional object is just to be an entity. We may call this the equivalence reading of $\mathrm{A}$ and formulate it as follows:

(A1) $a$ is an intentional object $\equiv a$ is an entity

where ' $\equiv$ ' stands for strict equivalence (or mutual entailment). On the second reading, which we may call the entailment reading of A, to be an intentional object is partly to be an entity:

(A2) $a$ is an intentional object $\vDash a$ is an entity

where ' $F$ ' stands for entailment. It seems to me that the reading relevant to our discussion is A2 rather than A1. The reason is that A1 is unnecessarily strong: if it were true, then — say — this table's being an entity would entail its being something someone is thinking about (or imagining or what have you). Unless you are a (Berkeleyan?) idealist, that will not do. But surely you can hold that non-existent intentional objects are problematic for the Straightfor- 
ward View without being a (Berkeleyan?) idealist. It therefore makes sense for us to work not with A, but with its left-to-right direction, A2: the claim, if you like, that to be an entity is a necessary, but not a sufficient condition for being an intentional object.

\section{Route 1}

As we have seen, it is crucial to Route 1 that one should argue against A, or rather (for the above reasons) A2, by appealing to the kinds to which intentional objects would have to belong if they were entities. Let us therefore state:

(B) To be an intentional object is to be an entity of a certain kind.

The strategy is then as follows (I will state it in terms of A2, because - recall - I have argued, and established, that it is the only reading of A that can be sensibly used in this context): claim that A2 entails $\mathrm{B}$; notice that B is false; conclude, by modus tollens, that A2 is false, too. Formally:

$$
\frac{\mathrm{A} 2 \vdash \mathrm{B} \quad \neg \mathrm{B}}{\neg \mathrm{A} 2}
$$

That Crane has something like this in mind in $I O$ is, I think, apparent. Here is how he states his strategy. There is, he says,

an assumption shared by both unacceptable positions [i.e., according to my nomenclature, the Propositional View and the Existence Defended View]: that to be an intentional object is to be a thing or an entity of a certain kind. ... The common assumption is that to be an intentional object is to be an entity. This is what I shall deny. ... What I am denying is that being an intentional object as such is being an entity of any kind. (Crane 2001: 340)

Here, the claims that to be an intentional object is (partly) to be an entity (A2) and that to be an intentional object is to be an entity of a certain kind (B) are treated, if we take Crane literally, as at least equivalent: they are both referred to as 'the assumption' shared by the Propositional View and the Existence Defended View. What Crane wants to do, however, is to deny that to be an intentional object is to be an entity — i.e., to deny A2 — by denying that being an 
intentional object is being an entity of any kind - i.e., by denying B. If this is Crane's strategy, then, it seems to me, there is no reason why he should require that $\mathrm{A} 2$ and $\mathrm{B}$ be equivalent - which, notice, is the only difference between Crane's strategy and Route 1 as I have characterised it. All he needs is an entailment from A2 to B. Thus, Crane's argument is really an implementation of Route 1.

$\mathrm{B}$, however, admits of more than one reading. In fact, it admits of four. It may be read as stating that to be an intentional object is just to be an entity of a certain kind, or as stating that to be an intentional object is partly to be an entity of a certain kind. Just as we did with claim A, we may call these the equivalence and the entailment reading of $\mathrm{B}$, respectively. This distinction is cross-cut by a second distinction. B may be read as stating that to be an intentional object is to be an entity of some kind or another (i.e., to be an entity such that there is a kind to which it belongs), or as stating that to be an intentional object is to be an entity of a specific kind. Call these the general and the specific reading of $\mathrm{B}$, respectively. We thus have the following available options: equivalence-generic (B1), entailment-generic (B2), equivalence-specific (B3), entailment-specific (B4).

The third and fourth readings require further elucidation: what is the specific kind in question? Crane seems to assume as a general principle that, as he puts it, "when something is a thing of a certain kind, there are general conditions that it meets which make it a thing of that kind" (Crane 2001: 341). I read this as a conditional: if something is a thing of a certain kind, then there are general conditions that it meets that make it a thing of that kind. Now, the idea that the intended conditions "make" an entity belong to a kind has a sufficiency-clause ring to it. However, judging from Crane's subsequent examples - "It is a necessary condition of being a mental event that it exhibits either consciousness or intentionality or both" — he rather thinks of the conditions as necessary. Therefore:

(P) If an entity $a$ belongs to a kind $k$, then it has certain features $K_{l}, \ldots, K_{n}$ such that, for any entity $x$, if $x$ belongs to $k$, then $x$ has $K_{l}, \ldots, K_{n}$

Under the specific reading, then, $B$ states that to be an intentional object is to be an entity that belongs to the kind to which all intentional objects belong - call it $\mathrm{K}$; and thus, given $(\mathrm{P})$, that to be an 
intentional object is to be an entity which has those features that any entity must have if it is to belong to $\mathrm{K}$.

Let us therefore state the four readings of $\mathrm{B}$ as follows:

(B1) $a$ is an intentional object $\equiv a$ is an entity of some kind or another;

(B2) $a$ is an intentional object $\vDash a$ is an entity of some kind or another;

(B3) $a$ is an intentional object $\equiv a$ is an entity of kind $\mathbf{K}$;

(B4) $a$ is an intentional object $\vDash a$ is an entity of kind $\mathbf{K}$.

This yields four lines of argument through which Route 1 may be implemented:

(1) A2 $\vDash B 1 ; \neg B 1$; therefore, $\neg \mathrm{A} 2$.

(2) A2 $\vDash B 2 ; ~ \neg B 2$; therefore, $\neg$ A2.

(3) A2 $\vDash B$ 3; $\neg$ B3; therefore, $\neg$ A2.

(4) A2 $\vDash B$ 4; $\neg$ B4; therefore, $\neg$ A2.

I will only focus on (2) and (4): as I will show, if these arguments are unsound, then (1) and (3) are, too. On the other hand, it is not entirely clear to me whether Crane has in mind the specific or the generic reading of B - i.e., whether his own argument is (2) or (4). As we shall see, there is some evidence that he has in mind the specific reading of B (i.e., B4), and therefore that his argument should be read as (4). So I will begin with the latter, and then go on to discuss (2) as well.

Argument (4) has two premises. First, that the claim that to be an intentional object is partly to be an entity entails the claim that to be an intentional object is partly to be an entity of kind $\boldsymbol{\kappa}$. Secondly, that the claim that to be an intentional object is partly to be an entity of kind $\mathrm{K}$ is false. Consider the first premise. The idea is that, if being an entity is a necessary condition for being an intentional object, on the other hand what it is for an entity to be an intentional object is to have some features that are necessary for its being an intentional 
object - for its belonging to kind $\boldsymbol{\kappa}$. Now, and this is the evidence I referred to above, Crane's arguments in $I O$, as far as Route 1 is concerned, are all intended to secure the second premise of (4), namely, claim $\neg$ B4 (viz., the claim that it is not the case that to be an intentional object is to be an entity of kind $\mathbf{k}$ ). In particular, Crane seems to argue, on the one hand, that we should only accept A2 if there are features that an entity needs to have to be an intentional object, and on the other hand that there are no such features. He writes:

When something is a thing of a certain kind, there are general conditions that it meets which make it a thing of that kind. ... There is no necessary condition which something must meet in order to be an intentional object, in the sense of there being something substantial that all intentional objects have in common ... There is nothing entities have to be, in general and in themselves, in order to be intentional objects. (Crane 2001: 341-342).

To be sure, all intentional objects are what some intentional state is about - they are the objects of a subject's thought (or desire or what have you). In this sense, they all share a qualification of sorts. However, and this is Crane's point, being what some intentional state is about is no feature of an entity (it is no condition that the entity itself satisfies): it is not a feature of the pine tree I see every day through my window that I am now thinking of it. This, one might point out, should not be particularly surprising: for it is intuitively awkward to say that "what some intentional state is about" denotes a kind. Again Crane:

Of course, it is true that all intentional objects are the objects of intentional states ... But this doesn't mean that the nature of intentional objects is to be the objects of intentional states, in the sense that the nature of physical objects is to have a certain spatio-temporal location and to have certain physical properties.... When a real thing is given or presented to a subject, there is nothing about it, considered in itself, which makes it the object of that subject's thought (Crane 2001: 342).

If this is correct, then claim B4 is false: it is not the case that to be an intentional object is to be an entity that meets necessary conditions for being an intentional object (i.e., for belonging to kind $\mathrm{K}$ ) - because there are no such conditions. Once we secure $\neg$ B4, we can proceed to deny A2 as per argument (4). 
There are at least two problems with this argument — I will discuss them in Section 6. There is, however, an alternative argument available to Crane, which turns on claim B2 (instead of B4): to be an intentional object is to be an entity of some kind or another. This is argument (2). The first premise is very plausible indeed. If to be an intentional object is partly to be an entity, then to be an intentional object is partly to be an entity that belongs to some kind or another: how could this be false? The thought that there might be an entity that does not belong to any kind seems sheer nonsense. The next move is to attack B2. Take Santa Claus and the round square cupola on Berkeley College: do they belong to any kind at all? As far as Santa is concerned, it is plausible to say that, had he existed, he would have belonged to some kind (e.g., he would have been human).

However, since Santa Claus does not exist, and thus (recall the assumptions made in Section 3) he is not an entity in any sense, it seems that he does not belong to any kind at all: for it is only entities that belong to kinds. Things are perhaps even more straightforward with the round square cupola on Berkeley College: indeed, since it could not even have existed, not only does it not, but it could not have belonged to any kind at all. ${ }^{2}$ If this is correct, then B2 is false: it is not the case that to be an intentional object is to be an entity of some kind or another, for there are some intentional objects that are of no kind, and even some that could not have been of any kind. Once we secure this, we can proceed to deny A2 as per argument (2).

\section{Route 2}

Route 2 attacks claim A, too, but does so in a different way. (Here I will be speaking of A instead of A2 because, as we shall see in

\footnotetext{
${ }^{2}$ A view that Crane has not abandoned: compare Crane 2013: 63. But also a view that, it is worth mentioning, is not entirely unexceptionable. Alberto Voltolini, for example, argues, discussing Crane, that "there are intentionalia that fall under a good category [i.e., a genuine kind] and yet do not exist" (Voltolini 2013: 402). If Voltolini's claim can be made good, argument (2) is flawed. However, since, as I believe and will show, argument (2) is flawed even if Voltolini is wrong, I will follow Crane in taking non-existent intentional objects not to belong to any kind, on the ground that it is only what exists that can, in principle, belong to some kind.
} 
Section 7, my objection to Route 2 is that Crane's argument, to be presented in a moment, refutes A but not A2.) The problem is, again, the relationship between being an intentional object and being an entity. Crane believes he can show that claim A is false, and that to be an intentional object is not to be an entity, as follows. Notice that, in ordinary talk, we sometimes speak of objects and of things, or entities, interchangeably. That is to say, in some and perhaps several contexts of ordinary language the term 'object' is synonymous with the terms 'thing' and 'entity'. For example, we speak of physical entities and physical objects alike, or of the thing, or the object, on that table. In other contexts, however, as Crane points out, the terms are definitely not synonymous. In such phrases as 'object of attention' and 'object of desire' (mark that both attention and desire are intentional states) we cannot substitute 'object' with 'thing' or 'entity'. This, Crane argues, would not be the case if intentional objects were, as such, entities: claim A entails the claim that 'object' and 'thing', or 'entity', are always intersubstitutable. But this claim is false. Therefore, again by modus tollens, the former claim, A, is false as well. See Crane 2001: 340-341.

\section{Route 1 blocked}

First consider argument (4):

$\mathrm{A} 2 \vDash \mathrm{B} 4 ; \neg \mathrm{B} 4$; therefore, $\neg \mathrm{A} 2$.

It is not clear to me that Crane is in a position to secure either premise.

Consider $\neg \mathrm{B} 4$ : it is not the case that to be an intentional object is (partly) to be an entity of kind $\mathrm{K}$ (i.e., of the kind to which intentional objects as such belong). Crane's argument for $\neg \mathrm{B} 4$, recall, is as follows. By principle (P), if an entity belongs to kind $\mathrm{K}$ it must have certain features $K_{1}, \ldots, K_{n}$ that are necessary for its belonging to $\mathrm{K}$; but there are no such features; therefore, no entity belongs to $\mathrm{K}$ - in principle. ${ }^{3}$ But then it cannot be true that to be an intentional object is (partly) to be an entity of kind $\mathrm{K}$ : because if it were true, then, since no entity can in principle belong to $K$, there would be no

\footnotetext{
${ }^{3}$ It also seems plausible to me that if there are no features that an entity must meet in order to belong to $\mathrm{K}$, there is no kind $\mathrm{K}$. But that is beside the point.
} 
intentional objects. Hence, $\neg \mathrm{B} 4$.

It seems to me that the argument is valid. But is it sound? There is room for doubt: because arguably there are features that an entity must have if it is to be an intentional object. For example, it will have to be self-identical. Thus, the second premise of the argument - i.e., the claim that there are no features that an entity must have if it is to be of kind $\mathrm{K}$ - is false, the conclusion is unwarranted, and $\neg \mathrm{B} 4$ is not secured.

True, Crane might have a couple of ways out. First, to claim that self-identity is a relation (of an entity with itself) rather than a feature. So it would be up to his opponent to come up with a genuine feature that did the trick (no one springs to mind). Second, to reformulate (P) by imposing a relevancy clause, and understand $K_{1}, \ldots, K_{n}$ not simply as necessary conditions for $x$ to belong to $k$ (in our case, to $\mathrm{K}$ ), but as relevant necessary conditions. This would rule out selfidentity and all the relations and features that are necessary for an entity to belong to any kind whatever.

Has either defence any potential? I am not sure. What this discussion clearly shows, however, is that it is at least not obvious that Crane is in a position to secure $\neg \mathrm{B} 4$, the second premise of argument (4). I will leave it at that, because, as I will argue presently, Crane has even bigger fish to fry, and a pan not nearly large enough.

So I concede to Crane that the second premise of argument (4), $\neg \mathrm{B} 4$, is true. What about the first premise, $\mathrm{A} 2 \vDash \mathrm{B} 4$ ? Contra Crane, I wish to argue that there is no such entailment — or, at the very least, that we have no reason to think there is. This is because A2 and B4 differ in their truth-conditions. Specifically, B4 seems to require more from the world (so to speak) than A2 does. The reason is that $\mathrm{B} 4$ carries an explicit commitment to the existence of kind $\mathrm{K}$ : for B4 to be true, $\boldsymbol{K}$ must exist. A2, on the other hand, carries no such explicit commitment: it is compatible with the claim that $\mathbf{K}$ (the kind to which intentional objects as such belong) does not exist. True, A2 might be implicitly committed to the existence of $\boldsymbol{\kappa}$. On such a view, the role of $\mathrm{B} 4$ in the argument would be to make the commitment explicit and thus available to Crane's attack. But is A2 implicitly committed to the existence of $\boldsymbol{K}$ ?

In order to decide the question, we need to know exactly what $\mathrm{K}$ is. And the burden is on Crane to tell us. Notice that $\mathrm{K}$ cannot be 
any trivial kind, such as, for example, the all-encompassing kind of the self-identical entities: because, recall the foregoing discussion, the features that an entity must have in order to belong to $K$ must be non-trivial (otherwise, premise $\neg \mathrm{B} 4$ is lost). The main point, however, is that Crane gives us no reason to take A2 to be even implicitly committed to the existence of $\boldsymbol{K}$. To such an extent, he fails to show that the truth-conditions of A2 are at least as demanding as those of $\mathrm{B} 4$, and thus fails to secure the entailment from A2 to B4. ${ }^{4}$

Argument (4), then, falls short of securing $\neg \mathrm{A} 2$ : its second premise is dubious, its first premise even more so.

Consider now argument (2). Here the first premise is true: if to be an intentional object is (partly) to be an entity, then surely it is to be an entity of some kind or another - as every entity must belong to some kind. The problem is the second premise, B2. For, recall, the reason why B2 is taken to be false is that some intentional objects do not exist, and therefore may not belong to any kind. But to say that some intentional objects do not exist is just to say that they are not entities; that is, the reason why B2 is false is that A2 is false. But that A2 is false is supposed to be the conclusion of the argument! If we already know that $\neg \mathrm{A} 2$, then surely we need not work our way through considerations about the kinds to which intentional objects would belong if they were entities: for we already know that they are not entities. In this sense, argument (2) effectively begs the question as to whether to be an intentional object is (partly) to be an entity, and thus collapses on whatever argument there is to attack A2 directly. Therefore, argument (2) is not a good way of defending the Straightforward View, either.

I have been focusing on arguments (2) and (4), and left (1) and (3) to one side. In Section 3 I gave the following reason for doing so: that, due to the nature of my objections, if they apply to (2) and (4), then they also apply to (1) and (3). I now wish to show that that is indeed the case. Consider (1) and (2). The only difference between them is that B1 occurs in (1) where B2 occurs in (2). Now, my objection to

\footnotetext{
${ }^{4}$ Notice that if there were reasons to think that A2 is implicitly committed to the existence of $\mathrm{K}$, then the role of B4 in the argument would be very minimal indeed: it would, after all, only be a reformulation of A2. At that point, I doubt that appealing to B4 would pay any substantial dividend.
} 
(2) turns on the fact that the only reason we seem to have to affirm its second premise, namely, $\neg \mathrm{B} 2$, is to deny A2: since $\neg \mathrm{A} 2$ is supposed to be the conclusion of the whole argument, so the objection goes, then the latter is either useless or question-begging. These considerations, it seems to me, readily transpose to argument (1). For why should we deny that the claims that to be an intentional object is to be an entity, and that to be an intentional object is to be an entity of some kind or another, are mutually entailing? That is, why should we affirm the second premise of (1), $\neg$ B1? The only option, as far as I can see, is to do so on the ground that some intentional objects are not entities - i.e., again by arguing that $\neg \mathrm{A} 2$. If that is so, then arguments (1) and (2) really suffer from the same difficulty.

Now consider (3) and (4). I put forward two objections to them. One, on which I did not put too much weight, is that Crane may not be in a position to secure $\neg \mathrm{B} 4$; the other, that Crane is definitely not in a position to secure $\mathrm{A} 2 \vDash \mathrm{B} 4$. How do these fare with respect to argument (3)?

The only difference between (3) and (4) is that B3 occurs in the former wherever B4 occurs in the latter. And the only difference between B3 and B4 is that, unlike B4, B3 is an equivalence (B4 is its left-to-right direction). Now, in order to push (3) through, Crane has to secure $\neg \mathrm{B} 3$. That can be achieved by securing the negation of either of its directions. If I am right, Crane is not in a position to secure the negation of the left-to-right direction, viz., $\neg \mathrm{B} 4$. If he is in a position to secure at least the negation of the right-to-left direction of B3, however, he is able to secure the negation of the whole equivalence. Is he in such a position? The right-to-left direction of $\mathrm{B} 3$ is the claim that if an entity $a$ is of kind $\mathrm{K}$, then $a$ is an intentional object. Since $\mathrm{K}$ is, by definition, the kind to which intentional objects as such belong, it seems that the claim that if an entity belongs to $K$ then it is an intentional object must be true. But then Crane can negate neither direction of $\mathrm{B} 3$, and therefore $\neg \mathrm{B} 3$ is out of his reach. Therefore, argument (3) is unsuccessful: partly for the same reason as (4), partly due to further issues.

The second objection transposes even more straightforwardly. Here is why. Notice that if, as was the case with (4), we have no reason to think that the truth-conditions of A2 are at least as demanding as those of $\mathrm{B} 3$, then we have no reason to think that the first premise 
of (3) - viz., the claim that A2 entails B3 - is true. And that seems to be so. Indeed, the only reason we would have to take the truthconditions of A2 as being at least as demanding as those of B3 is that $\mathrm{A} 2$ is at least implicitly committed to the existence of $\boldsymbol{\kappa}$ (because B3, just like B4, is explicitly committed to it). However, as I have already argued with respect to argument (4), Crane fails to give us any such reason. Therefore, arguments (3) and (4) really suffer from the same difficulties, and are both unsuccessful.

If all of this is correct, then Crane's way of implementing Route 1 in $I O$ falls short of securing the Straightforward View. On the other hand, the problem seems to be general rather than specific to Crane's own arguments: I fail to see how one might amend the latter so as to implement Route 1 in an effective way. Put otherwise, I do not see how one might try to defend the Straightforward View by appealing to the kinds to which intentional objects would belong if they were entities, and yet escape the difficulties of Crane's own arguments. This is easy to see with respect to arguments (1) and (2) - which I am not even sure are liable to be further generalised. As to arguments (3) and (4), in order to escape the objection one would have to show that the truth-conditions of claim A2 and those of claims $\mathrm{B} 3$ and B4 do not differ in the relevant sense, and that, therefore, $\mathrm{A} 2$ does entail B3 and B4. But how is one to achieve this? If the whole point of $\mathrm{B} 3$ and $\mathrm{B} 4$ is to bring a specific kind into the picture, namely, kind $\mathbf{K}$; and if the reason for this is that, as far as A2 is concerned, that kind is not in the picture; and if this is what Route 1, as a strategy, is all about; then it seems that the truth-conditions of $\mathrm{B} 3$ or B4, or of any counterpart of them in any alternative version of Route 1 must be more demanding than those of A2. If that is so, then there cannot be any entailment from A2 to B3 or B4, or to any of counterpart of the latter in any version of Route 1 . In this sense, trying to secure the Straightforward View through Route 1 seems quite generally a bad idea.

\section{Route 2 blocked}

It is not clear to me whether Crane really thinks that failure of intersusbstitutivity is enough to secure the claim that to be an intentional object is not to be an entity. Be that as it may, failure of intersubstitu- 
tivity seems, in fact, insufficient. Indeed, one is in a position to interpret the failure as indicating that 'object' simply has a richer connotation than 'entity' (or 'thing'). In this sense, the intersubstitutivity test does show that something more than being an entity is required for something to be an intentional object — namely, that someone thinks of the entity, or desires it, or what have you. What it does not show is that being an entity is not a requirement altogether — that it is not, at least, a necessary, albeit not a sufficient condition for being an intentional object. In other words, the intersubstitutivity test shows that claim A1 is false: to be an intentional object is not just to be an entity. As we have seen, however, A1 is too strong a claim, and opponents of the Straightforward View need not endorse it. More modestly, they can endorse A2. But A2 is precisely the claim that failure of intersubstitutivity fails to refute: that being an intentional object is partly to be an entity - that being an entity is a necessary, though not a sufficient condition for being an intentional object.

If this is correct, then it takes more than the intersubstitutivity test to show that to be an intentional object is not, at least partly, to be an entity.

This is not merely a problem of Crane's own way of implementing the strategy: there seems to be no way to amend the test so as to make the general Route- 2 case good. That is because synonymy is essentially an equivalence relation, and there is no way of inferring, from the sheer negation of an equivalence, the negation of either of its two directions. Of course, you can draw the inference if you know that one direction is false. But this is not helpful, here: for, in order to infer $\neg \mathrm{A} 2$ from $\neg \mathrm{A} 1$, you would first have to secure

$a$ is an entity $\vDash a$ is an intentional object.

But, as I have already pointed out, you can only do so under strong Idealistic assumptions. If that is so, then either Route 2 fails or it is committed to Idealism in a way, notice, that the Straightforward View is not. Thus, in general, Route 2 is not a good way to defend the view, for it only manages to do so (if it does at all) at the cost of imposing further and quite substantial commitments to it.

I said that, if my objection is sound, then it takes more than failure of intersubstitutivity to show that to be an intentional object is not, at least partly, to be an entity. To be fair, in $I O$ Crane has something 
more: a characterisation of what it is to be an intentional object in terms of relativity to a subject and of an assimilation of the notion of intentional object to that of a world in a non-metaphysical, subjectrelative sense. I believe that such a characterisation, if sufficiently developed and defended, might indeed give rise to a strong case against claim A both in the A1 and A2 readings, and thus in favour of the Straightforward View. Crane himself develops it elsewhere - in Crane 2013, for example. Others in the analytic literature have done so, too: see, for example, Smith 2002. As Crane (following Smith) points out, Husserl also held a similar view. However, this line of thought is nothing more than sketched in $I O$ : it does not make an argument. At best, it points to one. What is more important with respect to the value of Route 2, an argument built on a development of what we may call the subjective or phenomenological characterisation of the notion of intentional object might as well dispense with the intersubstitutivity test, which does not seem to be able to do any substantial work in it. If there is a way to make the Straightforward View good, then, it is not Route $2 .^{5}$

Nicola Spinelli

University of Warwick n.spinelli@warwick.ac.uk

\section{Bibliography}

Berto, Francesco. 2013. Modal meinongianism and actuality. Humana. Mente Journal of Philosophical Studies 25: 155-176.

Brentano, Franz. 2015. Psychology from the Empirical Standpoint. London: Routledge. Caston, Victor. 2001. Connecting traditions: Augustine and the Greeks on intentionality. In Ancient and Medieval Theories of Intentionality, ed. by Dominik Perler. Leiden: Brill.

Caston, Victor. 2007. Intentionality in Ancient philosophy. Stanford Encyclopedia of Philosophy (first published in 2003; last substantive revision in 2007).

${ }^{5}$ I am grateful to my audiences at the Warwick-London Mind Forum (KCL, February 2014), the Joint Session (Cambridge, July 2014), and the NTNU "Perspectives on Intentionality" conference (Fefor Høifjellshotell, Norway, September 2014). I am particularly grateful to Franz Berto, Tim Crane, J.C. Espejo-Serna, Paola Romero, David Smith, Alberto Voltolini and an anonymous reviewer for feedback and discussion. 
URL: http://plato.stanford.edu/entries/intentionality-ancient/ Crane, Tim. 2001. Intentional objects. Ratio 14: 336-349.

Crane, Tim. 2012. What is the problem of non-existence? Philosophia 40: 417-434.

Crane, Tim. 2013. The Objects of Thought. Oxford: Oxford University Press.

Kripke, Saul. 1980. Naming and Necessity. Cambridge, MA: Harvard University Press.

Meinong, Alexius. 1960. On the theory of objects. In Realism and the Background of Phenomenology, ed. by Roderick Chisholm. Glencoe, IL: Free Press.

Priest, Graham. 2005. Towards Non-Being. The Logic and Metaphysics of Intentionality. Oxford: Clarendon.

Russell, Bertrand. 1996. The Principles of Mathematics. New York/London: W.W. Norton \& Company.

Searle, John. 1893. Intentionality. An Essay in the Philosophy of Mind. Cambridge: Cambridge University Press.

Smith, Arthur David. 2002. The Problem of Perception. Cambridge, MA: Harvard University Press.

Voltolini, Alberto. 2013. There are intentionalia of which it is true that such objects do not exist. International Journal of Philosophical Studies 21 (3): 394-414. 